\title{
Disclosure of Sexual Orientation and Uptake of HIV Testing and Hepatitis Vaccination for Rural Men Who Have Sex With Men
}

\author{
Nicholas Metheny, MPH, RN \\ Rob Stephenson, $\mathrm{PbD}$
}

Department of Health Behavior and Biological Sciences, School of Nursing and Center for Sexuality and Health Disparities, University of Michigan, Ann Arbor, Michigan
Conflicts of interest: authors report none.

\section{CORRESPONDING AUTHOR}

Nicholas Metheny, MPH, RN

Center for Sexuality and Health Disparities Room 974, Wing D

300 North Ingalls St

Ann Arbor, MI 48109

metheny@umich.edu

\begin{abstract}
PURPOSE The decision and ability of primary care clinician to make recommendations for routine human immunodeficiency virus (HIV) testing and hepatitis A virus (HAV) and hepatitis B virus (HBV) vaccines are shaped by knowledge of their patient's risk behaviors. For men who have sex with men, such knowledge requires disclosure of same-sex sexual behavior or sexual identity.
\end{abstract}

METHODS Data were analyzed from a national survey of rural men who have sex with men $(N=319)$ to understand whether the disclosure of sexual identity to clinicians was associated with increased uptake of HIV testing and hepatitis vaccinations.

RESULTS We found that disclosure of sexual identity to clinicians was significantly associated $(\mathrm{OR}=1.26 ; 95 \% \mathrm{Cl}, 1.08-1.47)$ with uptake of routine HIV testing and HAV/HBV vaccination.

CONCLUSION Our finding reinforces the need for safe, nonjudgmental settings for patients to discuss their sexual identities freely with their clinicians.

Ann Fam Med 2016;14:155-158. doi: 10.1370/afm.1907.

\section{INTRODUCTION}

7 he prevalence of infection with the hepatitis A virus (HAV), hepatitis $B$ virus (HBV), and human immunodeficiency virus (HIV) is significantly higher among US men who have sex with men than among other adults of reproductive age. ${ }^{1,2}$ Recommendations for routine HIV testing and HAV/HBV vaccination are shaped by a clinician's knowledge of their patients' risk behaviors. For clinicians to know their patients' risk behaviors, men who have sex with men, and thus who are candidates for routine HIV testing and hepatitis vaccinations, ${ }^{1,2}$ must reveal same-sex sexual behaviors and, for some, sexual identities. Previous research has shown that clinicians who are aware of a patient's sexual orientation are more likely to make preventative health recommendations, such as HIV and sexually transmitted infection testing and hepatitis vaccination. ${ }^{3}$ The decision to reveal same-sex sexual behaviors or identity to a clinician may be shaped by patients' fears of experiencing stigma or discrimination, which may be heightened in rural areas where levels of homophobia and prejudice have found to be higher than in urban areas. ${ }^{4}$ In this analysis, we seek to understand whether the disclosure of sexual identity is associated with increased HIV testing and hepatitis vaccinations among a nationwide sample of rural men who have sex with men.

\section{METHODS}

Data were collected using an online, Facebook-recruited sample of men living in rural ZIP codes in the United States. Until recently, studies using Facebook for online recruitment of men who have sex with men targeted 
banner ads only to men who indicated a same-sex preference in the sexual orientation section of their profiles. One study found, however, that only $1 \%$ of men's Facebook profiles indicated a specific interest in other men. ${ }^{5}$ To reduce this bias, we targeted banner ads to the profiles of men who follow lesbian/gay/bisexual/ transgender (LGBT)-themed Facebook pages, such as advocacy groups, LGBT celebrities, LGBT communities, and campaigns. This approach offered a broader reach than restricting recruitment to sexual orientation alone and may also include men who have sex with men who do not identify as gay or bisexual. Rural status was determined based on the US Census Bureau's definition of areas with a population density of less than 1,000 people per square mile. ${ }^{6}$ After clicking on the banner ad, all respondents answered screening questions confirming that they met the inclusion criteria.

Internet-based research involving men who have sex with men is common, and there is little evidence to suggest that the samples of rural men recruited online are not representative of the larger population of rural men who have sex with men in the United States. In fact, evidence suggests that samples of men who have sex with men recruited via Facebook have the same demographic characteristics as those recruited using in-person, venue-based sampling. ${ }^{5}$ High levels of discrimination and homophobia in rural areas also means that men recruited through LGBT-oriented venues could be a biased sample of all rural men who have sex with men, representing only those who feel comfortable in LGBT-themed venues. ${ }^{7}$ Widespread Internet connectivity in the United States, even in rural areas, reduces concerns related to rural men who lack of internet access. ${ }^{8}$ Hence, an online survey offers a unique opportunity to reach a large, national sample of rural men who have sex with men.

Respondents self-reported whether they had ever received a vaccine for HAV or HBV and when they were most recently tested for HIV. Consistent with Centers for Disease Control and Prevention guidelines for adult men who have sex with men, ${ }^{9,10}$ a binary variable was created and coded as 1 if respondents reported receiving a HIV test in the past 12 months and if they had received a single dose of both the HAV and HBV vaccines. Although viral hepatitis prevention requires a 2-step (HAV) or 3-step (HBV) injection series, this study aimed to determine whether the vaccines were recommended by a clinician knowledgeable of the patient's sexual behaviors; hence, uptake of at least 1 vaccination was considered indicative of having been recommended. A single dose also allowed the inclusion of respondents who had not yet finished the HAV or HBV series. Disclosure to a clinician was measured on a validated scale ${ }^{11}$ ranging from 1, "My primary care pro- vider definitely does not know that I am gay," to 7, "My primary care provider definitely knows that I am gay and we talk about it openly." For those without a primary care clinician, respondents referred to a clinician they had seen most often in the past year. We fitted a logistic regression model to examine whether sexual orientation disclosure to a clinician was associated with receiving HIV testing and both hepatitis vaccinations. We controlled for age, race, employment status, education, and relationship status. The study was approved by the Emory University Institutional Review Board.

\section{RESULTS}

The final sample $(\mathrm{N}=319)$ included at least 1 respondent from all 50 US states. The mean age was 30.0 years $(\mathrm{SD}=11.74)_{i} 95.3 \%$ self-identified as gay (the remaining identifying as bisexual) $; 82.5 \%$ reported some form of medical insurance; and $72.1 \%$ reported having a primary health care clinician. The sample's HBV vaccination uptake of $50.5 \%$ is similar to that of other studies of men who have sex with men. ${ }^{12}$ In this sample of rural men who have sex with men, the percentage of those who had tested for HIV in the past 12 months was 37.3\%.

Less than one-fifth $(18.8 \%)$ reported receiving HIV testing and at least 1 dose of both hepatitis vaccinations (Table 1). Reporting of HIV testing and hepatitis vaccinations was marginally higher among younger men who have sex with men and those with a college education. Only disclosure to a clinician was significantly associated with receiving HIV testing and hepatitis vaccinations $(\mathrm{OR}=1.26, P=.004,95 \% \mathrm{CI}$, 1.08-1.47). Men who reported being out and talking openly to their clinicians about their sexual orientation were nearly $26 \%$ more likely to report having been tested for HIV and receiving at least 1 hepatitis vaccination. As Figure 1 illustrates, men who reported being fully out to their clinicians (reporting a 7 on the scale of sexual disclosure) were more likely to have received $\mathrm{HIV}$ testing and $\mathrm{HAV} / \mathrm{HBV}$ vaccinations than all other men (reporting 1 to 6 on the scale). Additionally, there was little difference in the outcome measures between those reporting a 1 and those reporting a 6 on the scale of sexual disclosure. Respondents who reported a 7 on the scale, however, were much more likely than any other group to have had a recent HIV test and $\mathrm{HAV} / \mathrm{HBV}$ vaccinations, suggesting a threshold effect whereby increased testing and vaccination is associated with full disclosure to the clinician.

\section{DISCUSSION}

The results of our analysis show a strong association between full disclosure of sexual orientation and 
Table 1. Sample Characteristics and Receipt of HIV Testing and HAV and HBV Vaccinations Among an Online Sample of Rural Men Who Have Sex With Men $(N=319)$

\begin{tabular}{|c|c|c|c|}
\hline Characteristic & $\begin{array}{l}\text { Respondents in } \\
\text { Each Category } \\
\% \text { (No.) }\end{array}$ & $\begin{array}{c}\text { Respondents With } \\
\text { Recent HIV Testing and } \\
\text { HAV and HBV Vaccinations } \\
\%\end{array}$ & $\begin{array}{c}\text { Respondents With } \\
\text { HIV Testing and } \\
\text { HAV and HBV Vaccinations } \\
\text { OR }(95 \% \mathrm{Cl})\end{array}$ \\
\hline Hepatitis A vaccination & $43.0(137)$ & $\ldots$ & $\ldots$ \\
\hline Hepatitis B vaccination & $50.5(161)$ & $\ldots$ & $\ldots$ \\
\hline HIV testing in the past 12 months & $37.3(108)$ & $\ldots$ & $\ldots$ \\
\hline HAV/HBV vaccination and HIV testing & $18.8(60)$ & $\ldots$ & $\ldots$ \\
\hline \multicolumn{4}{|l|}{ Age, y } \\
\hline $18-24$ & $48.0(153)$ & 20.3 & 1.00 [reference] \\
\hline $25-34$ & $24.8(79)$ & 19.00 & $0.64(0.29-1.42)$ \\
\hline $35-44$ & $11.9(38)$ & 15.8 & $0.43(0.14-1.28)$ \\
\hline$\geq 45$ & $15.4(49)$ & 16.3 & $0.44(0.16-1.17)$ \\
\hline \multicolumn{4}{|l|}{ Race } \\
\hline White & $89.7(286)$ & 18.9 & 1.00 [reference] \\
\hline Black/other & $10.3(33)$ & 18.2 & $0.98(0.36-2.65)$ \\
\hline \multicolumn{4}{|l|}{ Education } \\
\hline High school or less & $25.4(81)$ & 16.1 & 1.00 [reference] \\
\hline Some college & $51.1(163)$ & 19.6 & $1.36(0.64-2.87)$ \\
\hline College or higher & $23.5(75)$ & 20.0 & $1.42(0.59-3.46)$ \\
\hline \multicolumn{4}{|l|}{ Employment } \\
\hline Employed & $68.0(217)$ & 17.1 & 1.00 [reference] \\
\hline Unemployed & $10.3(33)$ & 21.2 & $1.60(0.60-4.28)$ \\
\hline Not in workforce & $21.6(69)$ & 23.2 & $1.57(0.77-3.19)$ \\
\hline \multicolumn{4}{|l|}{ Relationship status } \\
\hline Single & $62.1(198)$ & 18.7 & 1.00 [reference] \\
\hline Cohabiting & $22.3(71)$ & 21.1 & $1.13(0.55-2.30)$ \\
\hline Married, widowed, divorced & $15.7(50)$ & 16.0 & $0.83(0.33-2.09)$ \\
\hline \multicolumn{4}{|l|}{ Sexual orientation } \\
\hline Gay & $95.3(304)$ & 18.4 & $0.58(0.16-2.04)$ \\
\hline Mean disclosure to clinician $(1-7)^{\mathrm{a}}$ & $5.2(4.7-5.7)$ & $4.3(4.0-4.5)$ & $1.26(1.08-1.47)^{b}$ \\
\hline
\end{tabular}

receipt of important sexual health services. The sample was small and racially homogenous, and there was a risk of recall bias resulting self-reporting of receipt of services. Men reported receipt of HIV testing or hepatitis vaccinations but not the location where they received these services. It is therefore possible the men who are not out to their clinicians receive these services from other clinicians (eg, AIDS [acquired immunodeficiency syndrome] service organizations).

For rural men who have sex with men, being fully out to their clinician and talking openly about their sexuality is a fundamental gateway to receiving appropriate sexual health services. This finding reinforces evidence that clinicians make more population-specific preventative health recommendations when sexuality is freely discussed. ${ }^{3}$ Our analysis is the first of its kind to focus on rural men and begins to fill a gap in the literature concerning how such structural forces as homophobia and stigma shape health outcomes regarding the health care system for men who have sex with men in the United States. For disclosure of same-sex sexual behaviors to be universally achieved, there needs to be safe, nonjudgmental settings that allow for a 2-way conversation between patient and clinician. Although full disclosure to a primary clinician resulted in a significant increase in the odds of optimal uptake of HAV/HBV vaccinations and HIV testing, uptake of services in this rural sample were low. For example, HIV testing in the past 12 months (37\%) was well below a nationally representative sample of urban men $(61 \%))^{13}$ The overall low uptake of these services highlights the need for additional clinician-focused interventions to increase uptake of hepatitis vaccination and HIV testing in this population. Potential interventions include providing patients with talking points to empower them to discuss same- 


\section{Figure 1. Uptake of HIV testing and hepatitis vaccination by men reporting to being out to clinicians} among a nationwide sample of rural men who have sex with men in the United States.

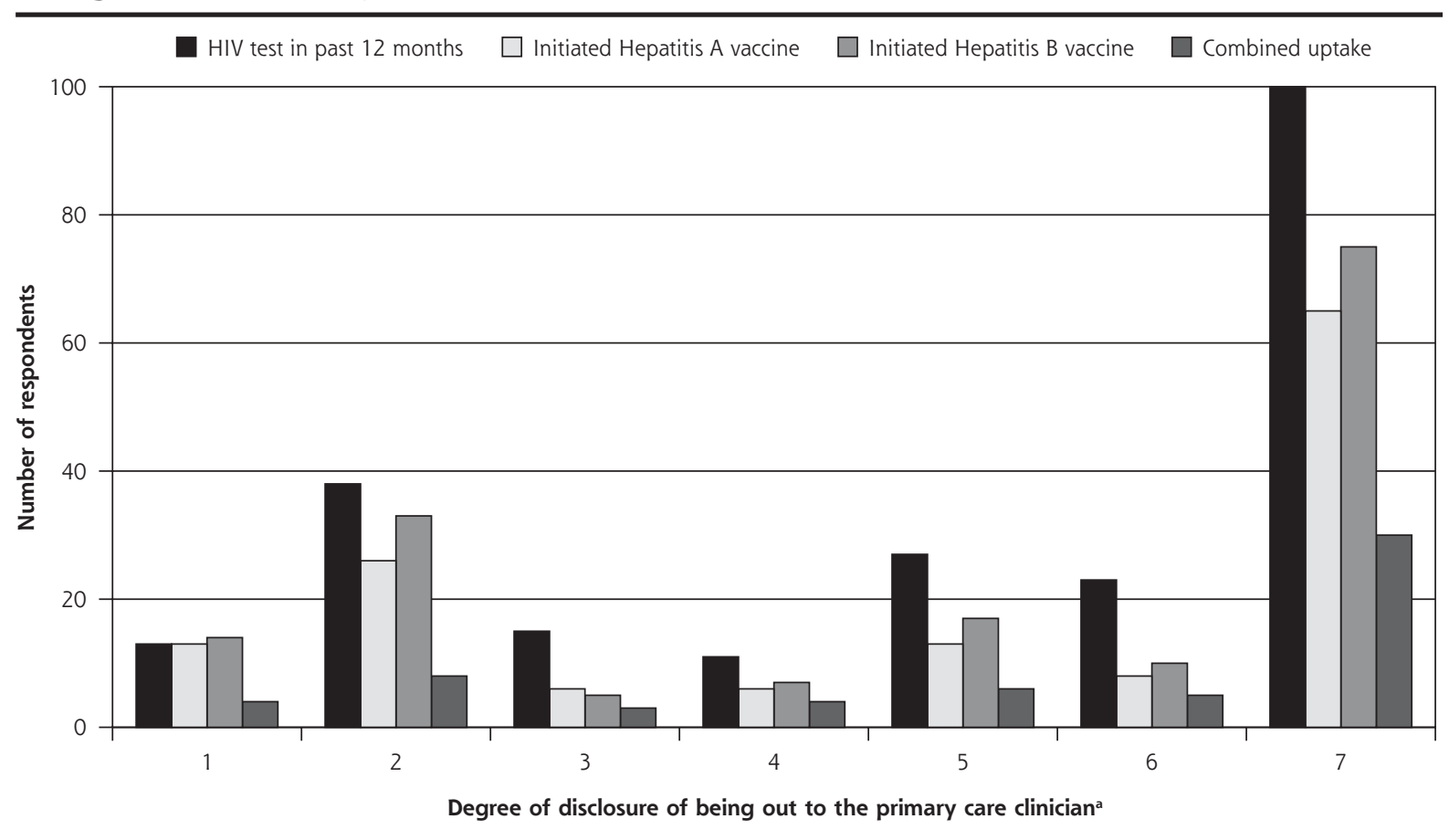

HAV = hepatitis A virus; HBV = hepatitis B virus; HIV = human immunodeficiency virus

a Based on a scale in which $1=$ no disclosure and $7=$ full disclosure of sexual orientation

sex sexual behaviors and/or sexual orientation with their clinician and sensitivity training for clinicians on appropriate ways to discuss sexuality and sexual behavior with their patients.

To read or post commentaries in response to this article, see it online at http://www.annfammed.org/content/14/2/155.

Key words: HIV, prevention $\&$ control; viral hepatitis vaccines; homosexuality; bisexuality

Submitted August 14, 2015; submitted, revised, November 30, 2015; accepted December 9, 2015.

\section{References}

1. Centers for Disease Control and Prevention. Viral hepatitis and men who have sex with men. http://www.cdc.gov/hepatitis/populations/ msm.htm. Accessed Jun 14, 2015.

2. Centers for Disease Control and Prevention. HIV Among Gay and Bisexual Men. http://www.cdc.gov/hiv/group/msm/index.html. Accessed Jun 14, 2015.

3. Petroll AE, Mosack KE. Physician awareness of sexual orientation and preventive health recommendations to men who have sex with men. Sex Transm Dis. 2011;38(1):63-67. Accessed June 16, 2015.

4. Preston DB, D'Augelli AR, Kassab CD, Starks MT. The relationship of stigma to the sexual risk behavior of rural men who have sex with men. AIDS Educ Prev. 2007;19(3):218-230. 10.1521/ aeap.2007.19.3.218 Accessed October 7, 2015.
5. Hernandez-Romieu A, Sullivan P, Sanchez T, Kelley C, Peterson J, Rio C, Rosenberg E. The comparability of men who have sex with men recruited from venue-time-space sampling and Facebook: a cohort study. JMIR Research Protocols JMIR Res Protoc. 2014;3(3).

6. Womach J, ed. Agriculture: A Glossary of Terms, Programs, and Laws. 2005 ed. Washington, DC: Congressional Research Service Reports; 2005. http://digital.library.unt.edu/explore/collections/CRSR/. Accessed Oct 7, 2015.

7. Bowen A. Internet sexuality research with rural men who have sex with men: can we recruit and retain them? J Sex Res. 2005;42(4): 317-323.

8. National Telecommunications and Information Association. National broadband map. 2015. http://www.broadbandmap.gov/. Accessed Nov 15, 2015.

9. Centers for Disease Control and Prevention. Gay and bisexual men's health- HIV/AIDS. http://www.cdc.gov/msmhealth/HIV.htm. Accessed Jul 3, 2015.

10. Centers for Disease Control and Prevention. Recommended adult immunization schedule- United States 2015. http://www.cdc.gov/ vaccines/schedules/downloads/adult/adult-combined-schedule.pdf. Accessed Jun 14, 2015.

11. Mohr J, Fassinger R. Measuring dimensions of lesbian and gay male experience. Meas Eval Couns Dev. 2000;33(2):66-90. Accessed Oct 7, 2015

12. Reiter PL, Brewer NT. Hepatitis B vaccination among a national sample of gay and bisexual men. Sex Transm Dis. 2011;38(3):235238. 10.1097/OLQ.0b013e3181f422bb Accessed October 7, 2015.

13. Centers for Disease Control and Prevention. HIV testing among men who have sex with men-21 cities, United States. 2008. http:// www.cdc.gov/mmwr/preview/mmwrhtml/mm6021a3.htm. Published August 12, 2015. Updated 2011. Accessed Oct 7, 2015. 